The daily urine output may be of low volume during the first few days of life especially in low birthweight infants. To lessen urine loss we apply silicone oil to all the drainage surfaces of the tray and scrape retained droplets of urine towards the drainage pipe using the rubber blade of a small window cleaner. Evaporative losses are reduced by nursing the child in humidified air.

There is no discomfort to the infant and the method is ethically and socially acceptable. Mothers can breast feed their infants under supervision, while any urine voided during the feed can be collected in a warmed receptacle placed under the female infant's buttocks, or positioned over the penis.

This device has greatly improved the accuracy and acceptability of prolonged urine collection for clinical and, especially, research purposes. The original model was constructed in stainless steel but it could be reproduced, in most research workshops, from a lighter and cheaper moulded plastic or Perspex.
We thank the Department of Medical Illustration for the photographs and Miss D Davis and Miss Rose-Marie Aikens for advice. The apparatus was constructed by Lawry Brice.

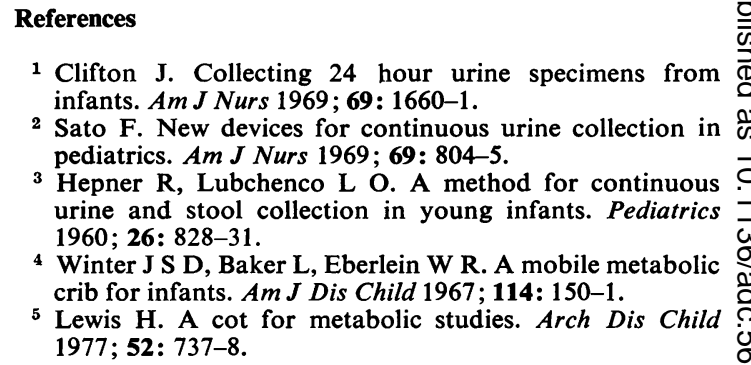

1 Clifton J. Collecting 24 hour urine specimens from infants. Am J Nurs 1969; 69: 1660-1.

2 Sato F. New devices for continuous urine collection in pediatrics. Am J Nurs 1969; 69: 804-5.

3 Hepner R, Lubchenco L O. A method for continuous urine and stool collection in young infants. Pediatrics 1960; 26: 828-31.

4 Winter J S D, Baker L, Eberlein W R. A mobile metabolic crib for infants. Am J Dis Child 1967; 114: 150-1.

5 Lewis H. A cot for metabolic studies. Arch Dis Child 1977; 52: 737-8.

Correspondence to $\operatorname{Dr} \mathrm{R}$ Johan Lund, 125 2nd Avenue, Kenilworth 7700, Republic of South Africa.

Received 6 April 1981

\title{
Chromosome 15 in floppy infants
}

\section{A CAROLINE BERRY, ALISON J WHITTINGHAM, AND BRIAN G R NEVILLE}

\section{Prince Philip Research Laboratories, Paediatric Research Unit and Newcomen Centre, Guy's Hospital Medical School, London}

\begin{abstract}
SUMmary Three children with Prader-Willi syndrome and chromosome abnormalities affecting chromosome 15 are described and the literature is reviewed. The usefulness of chromosome analysis in the investigation of the floppy infant is illustrated by two of the cases described. Twenty-three other children with similar clinical features had normal chromosomes.
\end{abstract}

The association of apparently balanced chromosome rearrangements involving chromosome 15 with Prader-Willi syndrome has been reported previously ${ }^{1-5}$ We wish to describe for the first time the presence of a $Y / 15$ translocation in a boy with this syndrome, and we also wish to describe 2 girls who presented in the neonatal period with extreme hypotonia and who too were found to have balanced translocations of chromosome 15.

\section{Case reports}

Case 1. This was the first son of healthy, unrelated parents who were each aged 26 years at the time of his birth. He has one healthy brother and his mother has had no miscarriages, $\mathrm{He}$ was a term, breech delivery and weighed $2.7 \mathrm{~kg}$ at birth. He was noted to be very floppy as an infant and did not sit unaided until age 18 months. No information is available about early feeding habits but he started to gain excess weight at about 9 months. He has had surgery to correct strabismus of the right eye but has no other medical problems. When seen at age 8 years he was attending a residential school for ESN (M) children and was making reasonable progress.

His height was on the 10th centile and his weight of $80 \mathrm{~kg}$ on the 97th centile and he was grossly obese, with fat distributed mainly around his chest and abdomen. He had a moon-shaped face with almond-shaped eyes, and a slight antimongoloid slant to the palpebral fissures. His penis was small and buried in fat and the scrotum hypoplastic. Neither testis was descended and they could not be palpated in the inguinal canal. His hands and feet were of normal size and he had a tendency to genu valgum. When last seen at age $11 \frac{1}{2}$ years his height was on the 15th centile and his weight was being controlled by an 800 -calorie diet maintained by his residential school. 
Chromosome analysis using $\mathrm{G}, \mathrm{C}$, and $\mathrm{Q}$ banding showed chromosome complement $45, \mathrm{X}, \mathrm{t}(\mathrm{Y} ; 15)$ (p11; q11) or $\operatorname{tdic}(\mathrm{Y} ; 15)(\mathrm{p} 11 ; \mathrm{p} 11)$.

The breakpoints were difficult to establish with certainty but there was some evidence from distamycin DAPI staining that 2 centromeres were present.

Both parents had normal chromosome complements.

Case 2. This girl was the first child of healthy unrelated parents who were aged 36 (father) and 25 (mother) years at the time of her birth. The mother had had one previous pregnancy which had ended in a first-trimester miscarriage. The pregnancy lasted 38 weeks; the mother commented on the lack of fetal movements and the baby girl was delivered by the breech. Birthweight was $3.46 \mathrm{~kg}$. Hypotonia, micrognathia, short neck with bilateral sternomastoid haematomas, and limited hip adduction were noted at birth and the baby fed very poorly so that tube feeding had to be introduced and continued for 3 months. A dislocated right hip was detected on day 3 and treated with a splint. Extreme hypotonia persisted and at age 4 months she had no head control, poor visual attention, and episodes of vertical eye rolling. There was weakness of all muscle groups but active movements could be provoked and tendon reflexes were preserved.

\section{Investigations}

The following gave normal results: serum creatine phosphokinase, thyroxine, electrolytes, and calcium concentrations, and the electromyogram. Chromosome analysis using $\mathrm{G}, \mathrm{C}$, and $\mathrm{Q}$ banding showed an apparently balanced Robertsonian translocation affecting chromosomes 13 and 15.

$$
45, \mathrm{XX}, \mathrm{t}(13 ; 15)(\mathrm{p} 11 ; \mathrm{q} 11) \text { or }(\mathrm{q} 11 ; \mathrm{p} 11)
$$

The father had a normal male chromosome complement. The mother had an identical chromosome complement to her daughter; her face had certain similarities to her daughter's; and she has since gained weight excessively.

The baby's management was complicated by the parents' initial rejection of her so that she remained in hospital until aged 4 months. Her social and visual responsiveness then improved and in the second 6 months of life her motor development showed rapid progress. Since then she has made slow but steady progress although she was obese by age 3 (height on 10 th centile, weight on 90th). When last seen at age 5 her psychological assessment showed that she was functioning in the upper end of the ESN (M) range of ability with motor immaturity, hypotonia, and fatiguability.
Case 3. This was the second daughter of healthy, unrelated parents who were aged 33 (father) and 35 (mother) years at the time of her birth. The mother's first pregnancy had ended in an early spontaneous abortion and the second one in the birth of a healthy daughter. More recently a healthy son has been born. Case 3 was born at term, with normal delivery, and a birthweight of $3.63 \mathrm{~kg}$. The mother was not aware of any paucity of fetal movements.

At birth pronounced micrognathia, mild talipes equinovarus, and extreme hypotonia were noted, and she had an episode of jerking interpreted as epilepsy during the first $\mathbf{2 4}$ hours. Tube feeding was required for several weeks. During this time she was found to have a tendency to flexion deformity of the fingers which responded to passive movements. She had no head control and made few active movements, but tendon reflexes were present.

\section{Investigations}

Serum creatine phosphokinase levels were normal, as were electromyogram and computerised tomography scan.

Chromosome analysis using Giemsa banding and distamycin DAPI staining showed the presence of a Robertsonian translocation affecting the two 15 homologues: $45, \mathrm{XX}, \mathrm{t}(15 ; 15)$ (p11 q11).

Both parents had normal chromosome complements.

This baby's management, too, was complicated by parental rejection and she was eventually sent to foster parents. She has made steady progress walking at age 3 years and with intellectual development proceeding at about two-thirds the normal rate.

\section{Discussion}

The relationship between chromosome rearrangement affecting chromosome 15 and the Prader-Willi syndrome has aroused curiosity ever since Hawkey and Smithies ${ }^{1}$ reported a $15 / 15$ translocation in a boy with Prader-Willi syndrome. Since then several further $15 / 15$ translocations ${ }^{2} 3$ and translocations between chromosomes 15 and other autosomes-for example $14^{4}$ and $3 \mathrm{p}^{5}$ - have been reported in individuals with features typical of this condition. No previous report of a Y/15 translocation in Prader-Willi syndrome is known to us although Subrt and Blehová $^{6}$ described a family in which several apparently normal males carried such a translocation while the abnormal propositus was described as severely hypotonic with pronounced psychomotor retardation and strabismus, but with no mention of hypogonadism.

Most children with Prader-Willi syndrome are chromosomally normal, and the clinical features in the neonate are well known. 
Since the initial report in 1976 we have karyotyped 26 children with hypotonia and features of PraderWilli syndrome and with the exception of these 3 cases all have given normal results, so that only about $10 \%$ of these children appear to be chromosomally abnormal. It would be interesting to see whether this group had clinical features which distinguished them in some way from the chromosomally normal Prader-Willi syndrome children, but no clear distinctions emerge.

Raised parental ages have been correlated with the presence of these particular chromosome abnormalities and this is to some extent borne out by our families as each of the female patients had one parent aged more than 35 .

The most striking clinical feature in these 2 children was their extreme hypotonia and weakness so that the differential diagnosis at the time of referral included Werdnig-Hoffmann disease and congenital muscular dystrophy. Both girls had skeletal defects (congenital dislocation of the hip in one, and mild talipes in the other) which indicated an intrauterine motor disorder.

Prader-Willi syndrome is a difficult diagnosis to make in girls, particularly in the newborn period, and the finding of the translocation allowed a guarded diagnosis of Prader-Willi syndrome as the likely cause for the hypotonia, and an appropriate prognosis could be given. In each case the child has developed the expected clinical features as she has grown older. It is significant that in both these children there was a failure of parental bonding, partly because of the lack of response in the infant and partly because the parents had been advised that this indicated that the child would be severely mentally retarded. This was because of the confusion between perinatal hypotonia in babies who had suffered severe intrapartum asphyxia and perinatal hypotonia in babies with the Prader-Willi syndrome. Only one child was finally accepted by her parents.

How the presence of a translocation affecting chromosome 15 leads to extreme hypotonia remains unexplained. In all reported cases the short arms of chromosome 15 are absent and despite the fact that they are heterochromatic in nature and therefore considered of no clinical significance, it is possible that loss of this region is the critical factor. In most reported cases the centromere is also absent although in the case reported by Emburger et $_{\text {al. }}{ }^{2}$ and in one of those described by Fraccaro et al., ${ }^{3}$ the $15 / 15$ translocation is dicentric. The most bizarre case is that reported by Le Jeune et al. ${ }^{7} \mathrm{~A}$ boy with typical extreme neonatal hypotonia and hypogonadism was found to have 3 cell lines. Each of these had a translocation affecting chromosome 15 and a second autosome $(5,8,12)$, the second autosome being different in each cell line. In each cell line the $\stackrel{\rho}{\mathcal{}}$ short arms and centromere of chromosome 15 were missing. In an important recent report, Ledbetter et al. ${ }^{8}$ described 4 children who had very small de- $\stackrel{0}{\rightarrow}$ letions of the proximal parts of the long arm of chromosome 15. Special techniques were used to $\stackrel{\overline{ }}{\bar{F}}$ produce extended chromosomes and the deletions $\frac{\bar{c}}{\square}$ had in several cases been missed using more conven- $\stackrel{\varnothing}{\varrho}$ tional techniques. However, Wisniewski et al. ${ }^{9}$ have $\stackrel{0}{\circ}$ reported a teenage boy with classical Prader-Willi features who appeared to have an extra marker chromosome which was shown to be made up of a $\vec{\omega}$ duplication of the short arms of chromosome 15, so $\stackrel{\omega}{\omega}$ that the picture is by no means straightforward. The earlier reported marker chromosomes generally have ? not been identified, but perhaps the crucial factor is of the balance of genetic information about the $15 \rightrightarrows$ centromere.

It must also be remembered that reciprocal $N_{N}^{\infty}$ translocations affecting chromosome 15 may not be 은 associated with any clinical abnormalities. There have been reports of families where a 15/15 translocation $Z$ was found in one of a couple presenting with multiple miscarriages. ${ }^{10}$

Translocations between 15 and 13, and between 15 웡 and 14 are much less common than those between 13 . and 14 but they can occur and are not generali $\oplus$ associated with any abnormalities. Our Case 2 has apparently normal mother with the same chromōं some complement, and in the family described by Smith and Noel $^{4}$ there are 3 asymptomatic translocation carriers. Genetic counselling for such individuals is very difficult and it would be puzzling to know what $\frac{}{\phi}$ action to advise if a fetus with an apparently balanced $\stackrel{\circ}{\Rightarrow}$ Robertsonian translocation affecting chromosome 15 is detected at amniocentesis.

\section{Conclusion}

Despite our lack of understanding of the underlying mechanisms, chromosome translocations, apparently윽 balanced and involving chromosome 15 , are not $\frac{3}{6}$ infrequently found in children with features of Prader-Willi syndrome and chromosome analysis $₹$ should be among the investigations of the 'floppy음 infant'.

We thank Dr O E Nietupska for permission to report case 1, and Professor P E Polani, Dr M G Daker, and ${ }^{\text {Cr }}$ Mr D E Mutton for constructive criticism and $\mathcal{N}$ interest.

The Spastics Society provided financial support.

\section{References \\ 1 Hawkey C J, Smithies A. The Prader Willi syndrome with a 15/15 translocation. J Med Genet 1976; 13: 152-6.}


${ }^{2}$ Emberger J M, Rodiere M, Astruc J, Brunel D. Syndrome de Prader Willi et translocation 15/15. Ann Genet (Paris) $1977 ; 20$ : 297-300.

3 Fraccaro M, Zuffardi O, Buhler E M, Jurik L P. 15/15 translocation in Prader Willi syndrome. J Med Genet $1977 ; 14: 275-8$.

4 Smith A, Noel M. A girl with the Prader Willi syndrome and Robertsonian translocation $45, X X, t(14 ; 15)$ (p11.q11) which was present in 3 normal family members. Hum Genet $1980 ; 55$ : 271-3.

5 Kucerová M, Straková M, Polivková Z. The Prader Willi syndrome with a $15 / 3$ translocation. J Med Genet 1979; 16: 234-5.

- Subrt I, Blehová B. Robertsonian translocation between chromosome $Y$ and 15. Hum Genet 1974; 23 : 305-9.

7 Le Jeune J, Maunoury C, Prieur M, Van der Akker J. Translocation sauteuse $(5 p ; 15 q),(8 q ; 15 q),(12 q ; 15 q)$. Ann Genet (Paris) 1979; 22: 210-3.
8 Ledbetter D H, Riccardi V M, Airhart S D, Strobel R J, Keenan B S, Crawford J D. Deletions of chromosome 15 as a cause of the Prader Willi syndrome. $N$ Engl J Med $1981 ; 304: 325-8$.

9 Wisniewski L P, Witt M E, Ginsberg-Fellner F, Wilner J, Desnick R J. Prader Willi syndrome and a bisatellited derivative of chromosome 15. Clin Genet 1980; 18: 42-7.

10 Bartsch-Sandhoff M. Letter: Fusion of homologous chromosomes (15q.15q) as cause of recurrent abortion. Lancet 1977; i: 551 .

Correspondence to Dr A Caroline Berry, Prince Philip Research Laboratories, Paediatric Research Unit, Guy's Tower, 8th Floor, St Thomas Street, London SE1 9RT.

Received 30 March 1981

\section{Galactosaemia: a new severe variant due to uridine diphosphate galactose-4-epimerase deficiency}

\section{J B HOLTON, M G GILLETT, R MACFAUL, AND R YOUNG}

\section{Department of Clinical Chemistry, Southmead Hospital, Bristol, and Department of Paediatrics and Department of Biochemistry, Pinderfields Hospital, Wakefield}

SUMMARY A baby presented on day 5 with symptoms of classical galactosaemia which are believed to be owing to a lack of uridine diphosphate-4-epimerase, rather than to the usual galactose-1-phosphate uridyl transferase defect. Apart from galactosaemia the condition was characterised biochemically by a red cell accumulation of galactose-1phosphate and uridine diphosphate galactose. Galactose restriction modified the acute clinical and biochemical abnormality, but it appears essential to include some galactose in the diet in this condition to allow synthesis of galactosides, including the brain gangliosides.

Classical galactosaemia which is caused by a deficiency of the enzyme galactose-1-phosphate uridyl transferase (transferase) often presents in the neonatal period with a severe illness characterised by vomiting, jaundice, failure to thrive, and hepatosplenomegaly, associated with excess of reducing substances in the urine. ${ }^{1}$ We wish to report a baby who presented on the fifth day of life with symptoms of classical galactosaemia apparently owing to an inherited deficiency of a different enzyme-namely, uridine diphosphate galactose-4-epimerase (epimerase). We know of no other reported case.

\section{Case report}

The patient, a girl, was born at term weighing $2490 \mathrm{~g}$ and was bottle fed from birth. She was the second child of a consanguineous marriage in a Pakistani family, the fathers of the parents being step-brothers with the same father. Jaundice, with a total serum bilirubin concentration of $121 \mu \mathrm{mol} / 1(7 \cdot 1 \mathrm{mg} / 100$ $\mathrm{ml})$ and direct of $37 \mu \mathrm{mol} / \mathrm{l}(2 \cdot 2 \mathrm{mg} / 100 \mathrm{ml})$, associated with secondary weight loss, was noted on the fifth day of life. The next day there was further weight loss, she became hypotonic, and had $0.75 \%$ reducing substances in her urine. On the ninth day occasional vomiting occurred, with continuing weight loss, jaundice, and hypotonia, and the liver edge was firm $-1 \mathrm{~cm}$ below the costal margin. Routine investigation of blood and CSF was normal, but galactose was found in the urine at a concentration of $116 \mathrm{mmol} / 1(2.09 \mathrm{~g} / 100 \mathrm{ml})$ and about this time a moderate generalised aminoaciduria was reported. The baby was given intravenous dextrose and, with a presumptive diagnosis of galactosaemia, was started on a low lactose diet in the form of Nutramigen feeds. The jaundice settled, liver function tests became normal, and she thrived from the 10th to 44th days of life. The Beutler screening test for transferase deficiency ${ }^{2}$ was negative on the 16th day of life and therefore she was challenged with Cow and Gate V formula for $2 \frac{1}{2}$ days, starting on the 44th day. Galactosuria returned within 24 hours and the serum transaminases became greatly increased with ALT $1473 \mathrm{U} / 1$ and AST $1218 \mathrm{U} / 1$ (normal values up to 48 and 43 respectively). Jaundice reappeared 